\title{
The protection of Alpine open spaces and the Alpine Convention - a timeline
}

\author{
Peter Haßlacher, Head of CIPRA Austria
}

25 years ago, on 7 November 1991, the Alpine Convention was signed in Salzburg. This marked the start of a hot phase of negotiations on the implementation protocols, which ended with the VI. Alpine Conference in Luzern in the year 2000. Initially the Alpine Convention was conceived as an agreement to protect the environment and to preserve the Alps as a living space for humans (Alpine Protection Convention). After a special intervention by the Swiss delegation the agreement was renamed Alpine Convention and the Spatial Planning Protocol augmented to Spatial Planning and Sustainable Development. A welcome step, designed to safeguard the Convention against any over-emphasis on exclusive protection.

In the more recent phase of the Alpine Convention process, and especially with the transition from the German presidency at the end of 2016 to the Austrian presidency for $2017 / 18$, the emphasis seems swapped around: There is little evidence left of any Alpine Spatial Planning with a strategic focus on the protection of Alpine open spaces. CIPRA, the International Commission for the Protection of the Alps, in the run-up to the meeting of the spatial planning ministers of the contracting parties on 18 April 2016 in Murnau, Germany, urged for putting this topic higher up the agenda because of currently intensifying touristic developments. And yet such issues show up neither in the Declaration Spatial Planning and Sustainable Development nor in the agreements of the XIV. Alpine Conference of October 2016 in Grassau (Germany). These developments may pose a threat of dissecting whole mountain ranges, collide with large protected areas, mean more traffic and increased consumption of land, as well as a possible revocation of the Bavarian Alpine Plan, which has existed unchanged for 44 years. Nor does the mandate to continue the ad hoc group of spatial planning experts or the working programme of the Austrian presidency of the Alpine Convention take up this Alpine key conflict. For Alpine politicians the agreements on the declaration of the XIV. Alpine Conference 2016 on Supporting a sustainable economy in the Alps and on Creating a comprehensive and ambitious action programme for a green economy within the Alpine Space seem much better suited to the implementation concept of the Alpine Convention than the initial demand of 25 years ago for limits to development in the Alps.

Alpine-political activities have been rather restrained in the search for solutions and in the implementation of the difficult and inconvenient points from the protocols in the fields of transport, tourism, land protection and spatial planning. There is an urgent need for a pan-Alpine debate about the practically unhampered growth of tourism, with the construction of ever more comprehensive infrastructure at ever higher altitudes and the litigious competition of destinations. Existing Alpine protected areas in the form of national parks, biosphere reserves, World Natural Heritage sites and FFH areas are too few and in too isolated locations, and nature parks are too feeble in their planning effect. These small islands across the Alpine arc must forge stronger links and networks to ensure the continued existence of Alpine open spaces without technical infrastructure and noise - not least as historically grown mountain farming landscapes. The Alpine Convention, as a bridge between contracting parties and monitoring organizations, is a feasible platform to achieve this.

Could it be that the expectations of the relevant observers were too high or that a strategic, pro-active management for implementing such a comprehensive international agreement was simply missing? Doubtless the resolutions of the I. Minister Conference 1989 in Berchtesgaden and various points of the implementation protocols raised hopes and expectations, especially in large circles of civil society. These expectations and hopes formed the basis for the support and involvement of actors in this implementation process. Points 37 and 60 of the Berchtesgaden Resolution to "keep the largest possible areas free from large technical development", "create large-scale zones of protection and retreat" and "cooperate, especially on designating large zones where no touristic development is allowed" initially suggested a strong political will of the contracting parties to implement a new Alpine spatial planning architecture. This was underlined by the inclusion of areas of respect and tranquillity (Ruhezonen) in the protocols on tourism, conservation and spatial planning.

Given the lack of action by the Alpine Convention in terms of the protection of Alpine open spaces within Alpine spatial planning, it is good to see this topic reintroduced into scientific spatial planning debates. It follows the establishment of the Bavarian Alpine Plan, the creation of the Tyrolean Landscape Plan and of the refugia (Ruhegebiete) conceived for Tyrol. The international working group Alpiner Freiraumschutz - Unerschlossene Alpine Zonen (UAZ) und deren raumordnerische Sicherung of the Academy for Spatial Research and Planning, Hannover (Germany), has started to put this topic to the fore, initially within the German-speaking Alps. For 2017/2018 CIPRA Austria will also focus on integrated and future-oriented Alpine spatial planning for the benefit of humans and nature. It plans a workshop on implementing the protocol Spatial Planning and Sustainable Development and an international conference on Alpine Spatial Planning. With these efforts, CIPRA aims to make the Alpine Convention balance the economy and the protection of the Alps in a way that will do justice to future generations.

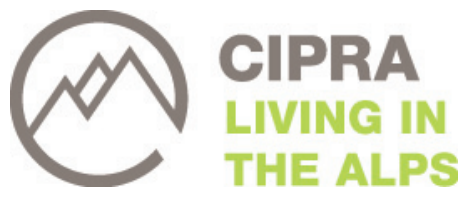

